\title{
Methotrexate-induced pancytopenia in a patient with ectopic pregnancy
}

Shih-Chieh Shao ${ }^{1}$, Yea-Huei Kao Yang ${ }^{2}$, Po-Shien Chien ${ }^{3}$, Edward Chia-Cheng Lai ${ }^{2}$

\begin{abstract}
${ }^{1}$ Department of Pharmacy, Chang Gung Memorial Hospital, Keelung, Taiwan

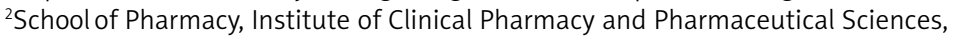
College of Medicine, National Cheng Kung University, Tainan, Taiwan

${ }^{3}$ Department of Obstetrics and Gynecology, Keelung Hospital, Ministry of Health and Welfare, Keelung, Taiwan
\end{abstract}

Submitted: 27 September 2015

Accepted: 6 October 2015

Arch Med Sci 2018; 14, 2: 475-476

DOI: $10.5114 /$ aoms.2016.58844

Copyright @ 2016 Termedia \& Banach

Methotrexate (MTX) has been used as the primary treatment for ectopic pregnancies; however; it raises the risk of a life-threatening adverse drug reaction such as pancytopenia [1]. We present a case of MTX-induced pancytopenia in a patient with ectopic pregnancy, which may be idiosyncratic and perhaps unavoidable, and we identify a few early signs of MTX toxicity that might assist in monitoring in order to minimize unintended consequences in patients.

A 27-year-old woman (gravida 2 and para 1), whose body surface area was $1.46 \mathrm{~kg} / \mathrm{m}^{2}$, presented without contributory medical history. She was diagnosed with ectopic pregnancy based on the findings of an ultrasound scan (ectopic mass: $1.9 \mathrm{~cm})$ and hCG titer $(1774.8 \mathrm{mlU} / \mathrm{ml})$. In pre-treatment evaluations, hemoglobin $(\mathrm{Hb}: 13.1 \mathrm{~g} / \mathrm{dl})$, white blood cells (WBC: $\left.7.72 \times 10^{9} / \mathrm{l}\right)$, platelet count $\left(262 \times 10^{9} / \mathrm{l}\right)$, blood urea nitrogen $(8 \mathrm{mg} / \mathrm{dl})$, serum creatinine $(0.51 \mathrm{mg} / \mathrm{dl})$, aspartate aminotransferase $(11 \mathrm{U} / \mathrm{l})$, and alanine aminotransferase $(11 \mathrm{U} / \mathrm{l})$ were in the normal range. She was subsequently administered a single dose of 50 mg MTX intramuscularly; however, on day 4 after MTX initiation she presented with severe vomiting and mucositis, which limited her daily dietary intake. On day 6 , she went to the emergency service due to fever $\left(39.3^{\circ} \mathrm{C}\right)$. Although her vital signs were stable (blood pressure: 103/66 mm Hg, pulse rate: 91 beats/min, respiratory rate: 20 breaths/min), hematological assessment revealed febrile neutropenia (WBC: $0.7 \times 10^{9} / \mathrm{l}$, neutrophils: $27.0 \%, \mathrm{Hb}: 11.5 \mathrm{~g} / \mathrm{dl}$; platelet count: $\left.174 \times 10^{9} / \mathrm{l}\right)$. She received a granulocyte colony-stimulating factor agent (filgrastim $300 \mu \mathrm{g} /$ day) and an empiric broad-spectrum antibiotic for febrile neutropenia. Because her prior complete blood counts were normal, we suspected MTX as the likely cause of neutropenia. She started leucovorin $120 \mathrm{mg} /$ day as a rescue therapy on day 7 , but anemia (nadir of $\mathrm{Hb}$ was $8 \mathrm{~g} / \mathrm{dl}$ on day 10; hematocrit: $23.5 \%$; mean cell volume: $92.2 \mathrm{fl}$ ) and thrombocytopenia (nadir of platelet count was $11 \times 10^{9} /$ I on day 12 ) were found on the following days. Although bone marrow evaluations were indicated to rule out malignancy and myelodysplasia, the patient did not accept a biopsy. She was transfused with blood products including packed red blood cells and platelets. Her hematologic parameters returned to the normal range and her condition improved gradually after 3 weeks from admission.

Pancytopenia has been reported in $3 \%$ of patients with rheumatoid arthritis receiving MTX, and the risk has been found to be associated with cumulative exposure [2]; however, the occurrence of pancytopenia

\author{
Corresponding author: \\ Edward Chia-Cheng Lai PhD \\ School of Pharmacy \\ Institute of Clinical Pharmacy \\ and Pharmaceutical Sciences \\ College of Medicine \\ National Cheng Kung \\ University \\ No. 1, University Road \\ Tainan 701, Taiwan \\ Phone: +886-6-2353535 \\ E-mail: tb8991010@mail. \\ ncku.edu.tw
}




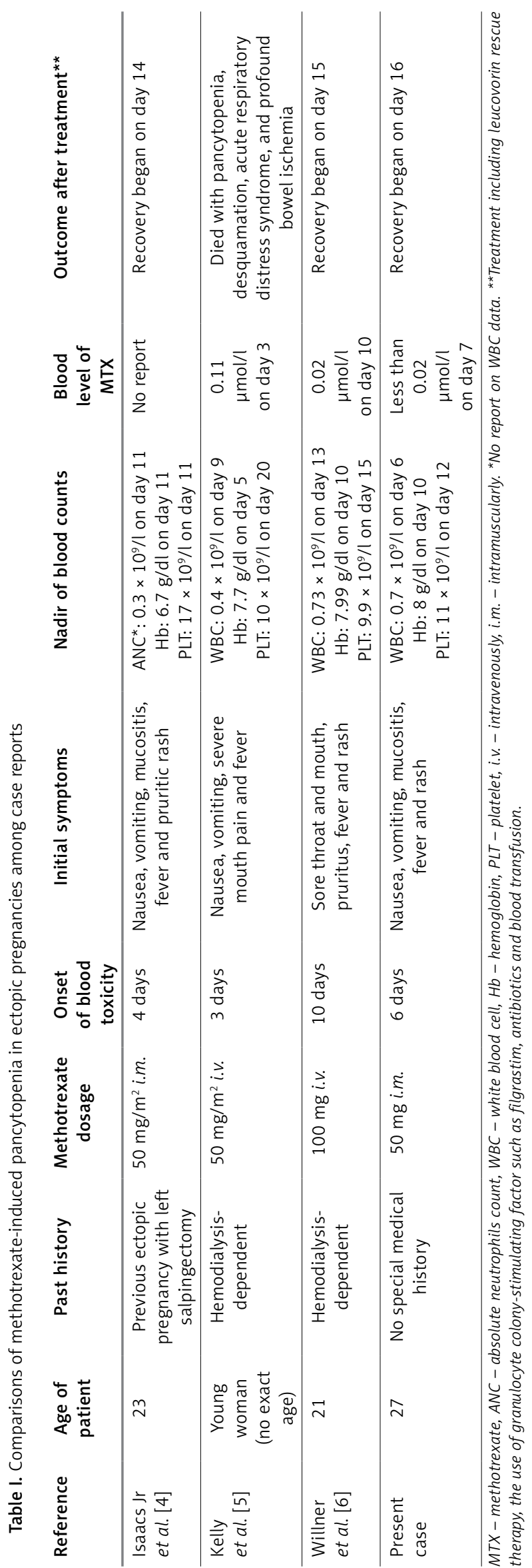

in the early stage with a single MTX injection is rare [3]. So far, only 4 cases, including the present one, of single-dose MTX-induced pancytopenia in patients with ectopic pregnancies have been reported [4-6] (Table I).

We found that the blood counts reached a nadir 10 days after MTX initiation and in most cases recovered by 14 days; furthermore, we found that in most cases initial symptoms were gastrointestinal upsets and oral ulcerations, which could be considered early signs of MTX-induced pancytopenia because cells with a high turnover rate such as in the gastrointestinal tract or oral mucosa are more susceptible to the cytocidal effects of MTX [2]. All the similarities to previous reports support the association between MTX and pancytopenia in the present case, including the onset of blood toxicity, initial symptoms, time to nadir of blood counts and time to recovery. However, it is noteworthy that the patient did not have concurrent predisposing factors such as renal dysfunction or concomitant use of other medications associated with pancytopenia or potential drug interactions with MTX [7].

Although MTX-induced pancytopenia is rare, physicians should be aware of such life-threatening adverse drug reactions from a single-dose MTX regimen in ectopic pregnancies. We suggest that health care providers and patients should monitor early signs and symptoms of MTX toxicity such as oral and gastrointestinal side effects to minimize unintended life-threatening events and consequences.

\section{Conflicts of interest}

The authors declare no conflict of interest.

\section{References}

1. Practice Committee of American Society for Reproductive Medicine. Medical treatment of ectopic pregnancy: a committee opinion. Fertil Steril 2013; 100: 638-44.

2. Lim AY, Gaffney K, Scott DG. Methotrexate-induced pancytopenia: serious and under-reported? Our experience of 25 cases in 5 years. Rheumatology 2005; 44: 1051-5.

3. Gungorduk K, Asicioglu O, Yildirim G, Gungorduk OC, Besimoglu B, Ark C. Comparison of single-dose and two-dose methotrexate protocols for the treatment of unruptured ectopic pregnancy. J Obstet Gynaecol 2011; 31: 330-4.

4. Isaacs JD Jr, McGehee RP, Cowan BD. Life-threatening neutropenia following methotrexate treatment of ectopic pregnancy: a report of two cases. Obstet Gynecol 1996; 88: 694-6.

5. Kelly H, Harvey D, Moll S. A cautionary tale: fatal outcome of methotrexate therapy given for management of ectopic pregnancy. Obstet Gynecol 2006; 107: 439-41.

6. Willner N, Storch S, Tadmor T, Schiff E. Almost a tragedy: severe methotrexate toxicity in a hemodialysis patient treated for ectopic pregnancy. Eur J Clin Pharmacol 2014; 70: 261-3.

7. Sosin M, Handa S. Low dose methotrexate and bone marrow suppression. BMJ 2003; 326: 266-7. 